\title{
Is High Sensitive-Troponin I A Reliable Biomarker For Cardiac Injury In Methadone Toxicity? A Prospective Cross-Sectional Study
}

\author{
Hasan Shemirani \\ Isfahan University of Medical Sciences \\ Masoumeh Sadeghi \\ Isfahan University of Medical Sciences \\ Azadeh Davoudian Dehkordi \\ Isfahan University of Medical Sciences \\ Farzad Gheshlaghi ( $\square$ gheshlaghi@med.mui.ac.ir) \\ Isfahan University of Medical Sciences
}

\section{Research Article}

Keywords: Methadone, High-sensitivity troponin I, Electrocardiography, Poisoning, Echocardiography

Posted Date: October 7th, 2021

DOl: https://doi.org/10.21203/rs.3.rs-769167/v1

License: () (i) This work is licensed under a Creative Commons Attribution 4.0 International License. Read Full License 


\section{Abstract}

Background: Methadone is a synthetic opioid mostly used for detoxification therapy, as its use increases; the possibility for methadone-induced cardiotoxicity may rise. The aim of this study was to determine the association of high-sensitivity troponin I levels as a predictor of cardiac injury in methadone toxicity.

Methods: Sixty methadone toxicity patients included in this prospective cross-sectional study from October 2018-November 2020. High-sensitivity troponin I level and electrocardiogram were assessed in patients at admission. All patients underwent echocardiography at admission and 30 days later and compared this findings between two groups based on high-sensitivity troponin I results.

Results: Mean age of the patients was $34.5 \pm 11.1$ years (males: $66 \%)$. Twelve $(20 \%)$ patients had positive high sensitive-troponin results. Long QT interval and inverted T in precordial leads were mostly observed in individuals with positive high-sensitivity troponin I $(75 \%$ vs. $35 \%, P=0.013$ and $83 \%$ vs. $16 \%, P<0.001$, respectively). Patients with elevated troponin had reduced left ventricular ejection fraction in comparison to normal group during admission $(43.1 \pm 15.4 \%$ vs. $55 \%, P<0.001)$ and this left ventricular ejection fraction remained abnormal after 30 days $(43.7 \pm 21.6 \%)$. Patients in positive high-sensitivity troponin I group had higher regional wall motion abnormality frequency both at admission and 30 days later compared to the other group ( 0 day: $42 \%$ vs. $0, P<0.001,30$ th days: $25 \%$ vs. $4 \%, P=0.020$ ).

Conclusion: Patients with simultaneous methadone toxicity and positive high-sensitivity troponin I had worse cardiac outcomes and this biomarker could be probably used for better implementation of therapeutic interventions and prognosis.

\section{Introduction:}

Methadone is a synthetic opioid agent with analgesic properties used for severe pain management. Moreover, methadone is widely used in maintenance treatment of opioid addiction [1]. It has been reported that approximately 750000 individuals are under methadone maintenance therapy (MMT) programs worldwide [2]. Due to the availability of methadone for MMT program, intentional and accidental poisoning is to be expected [1]. In recent years, Iran has perceived an shocking increase in the incidence of methadone poisoning, possibly due to easier access to opioids in adults and children [3-7].

According to DPIC's reports methadone is one of the most common causes for admission of poisoned patients in the toxicology emergency departments in Iran. [8].

Methadone is highly lipid soluble with $60-90 \%$ protein bounding. Its bioavailability ranges $70 \%-90 \%$ and essentially eliminated via liver metabolism $[9,10]$.

Methadone is not a safe drug and in overdoses it causes severe central nervous system depression as well as skin, gastrointestinal tract, and urogenital and cardiovascular involvement. Cardiotoxicity is one of the most serious and lethal side effects of methadone poisoning. Complications such as increased QT dispersion, QT interval prolongation, and torsade de pointes (TDP), Takotsubo cardiomyopathy, and Brugada-like syndrome were reported [11, 12]. 
Methadone causes hemodynamic instability by decrease peripheral vascular resistance, heart rate, and decrease 02 saturation [13].

The cardiotoxicity of methadone is reported in the literature. Ehret et al. reported methadone increase QT interval in consumers rather than non-consumers $(16.2 \%$ vs. $0, P<0.001)$ and had correlation with daily dosage of methadone usage $(r: 0.20, P<0.01)[14]$.

Rahimdarabad et al. reported that coronary artery diseases were more prevalent in methadone user [15]. In another study authors indicated that opium usage could be as an independent risk factor for manifestation of cardiovascular diseases [16]. In contrast, Dehghani concluded that the anterior myocardial infarction and related early mortality were lower in opium consumers [17].

hs-Tnl is a reliable biomarker for detection of acute coronary syndromes. An abnormal ECG in the presence of a positive marker is strongly indicative of myocardial infarction (MI). A variety of diseases such as atrial fibrillation, sepsis, heart failure, myocarditis, pulmonary edema, renal disease, myocardial contusion, direct myocardial damage, coronary spasm, burns and acute stroke can elevate hs-Tnl levels in the absence of acute coronary syndrome. On the contrary, hs-Tnl is not specific for the acute thrombotic occlusion of a coronary artery [18].

The aim of this study was to determine the association of hs-Tnl levels as a predictor of cardiac injury in methadone toxicity.

\section{Materials And Methods:}

\section{Study design and setting}

In a single center prospective cross-sectional study, all patients with methadone overdose diagnosis based on history confirmed by positive urine test admitted to Clinical Toxicology department of teaching Hospital between October 2018 to November 2020 were enrolled.

\section{Participants}

All hospitalized adult and adolescents patients more than 16 years old with methadone poisoning, regardless of their age or sex, were included. We excluded patients with underlying liver or renal diseases, cotoxicity of drugs or other opioids, any past medical history of cardiovascular disease and chronic alcoholism. After implementation of inclusion and exclusion criteria, a total of 60 patients were recruited in this study.

\section{Data gathering}

Demographic characteristics, occupation (employed/unemployed), cigarette smoking, hubble-bubble and alcohol as well as chronic methadone use were gathered through self-made questionnaire. At admission, heart rates (beats/minute), systolic/ diastolic blood pressure $(\mathrm{mmHg})$, respiratory rates (rates/minute), $\mathrm{O}_{2}$ saturation (\%), Hemoglobin (mg/dl), white blood cells (WBC) $\left({ }^{*} 10^{6} / \mathrm{l}\right)$, blood urea nitrogen (BUN), Creatinine 
$(\mathrm{Cr})(\mathrm{mg} / \mathrm{dl})$ measured. According to severity of methadone toxicities, patients were distinct into three categories including mild (respiratory rates: 6-8/minute and $\mathrm{O}_{2}$ saturation: $80-95 \%$ ), moderate (respiratory rates: 4-6/minute and $\mathrm{O}_{2}$ saturation: $60-80 \%$ ) and severe (apnea and $\mathrm{O}_{2}$ saturation $<60 \%$ ) [19]. hs-Tnl (VIDAS, France) measured at admission and patients categorized to positive or negative groups. hs-Tnl level of less than 0.04 considered negative, 0.04 to 0.06 suspicious and more than 0.06 positive. ECG was recorded and the following parameters assessed: sinus tachycardia, inverted T in precordial and limb leads, long QT interval (males $>440 \mathrm{msec}$ and females $>460 \mathrm{msec}$ ) and QRS variations. Echocardiography was performed for all patients (Samsung, hs40, 2017), cardiac condition and function included LVEF (\%), diastolic dysfunction (\%), regional wall motion abnormality (RWMA) (\%), left ventricle size dilation (\%), mitral regurgitation (MR) (\%), tricuspid regurgitation (TR) (\%) and pulmonary arterial pressure (PAP) $(\mathrm{mmHg})$ were evaluated. The same cardiologist reassessed participants 30 days later and measured all abovementioned cardiac parameters.

\section{Statistical Analysis:}

The data were analyzed using Statistical Package for Social Sciences (SPSS) version 21 (IBM Corp., Armonk, NY, USA). Nominal and numerical variables were reported as frequency (percentage) and mean \pm standard deviation, respectively. In order to evaluate the relation between categorical and continuous variables across different categories of hs-Tnl at baseline and at the end of follow-up, we used chi-square and student-t test, respectively. Paired-t test and McNemar tests used for assessment of correlation between hs-Tnl positive and negative groups in 1st and 30th day, as appropriate. A $P$ value of less than 0.05 was considered statistically significant.

\section{Results:}

Sixty patients with the mean age of $41.51 \pm 17.82$ (range; 17 to 58 ) years, $40(66 \%)$ were men were included with methadone poisoning during the study period. From the total of 60 recruited patients, $12(20 \%)$ had positive High-sensitivity troponin I (hs-Tnl) levels. General characteristics of study population based on positive or negative results of High-sensitivity troponin I (hs-Tnl) are illustrated in Table 1. History of alcohol abuse was significantly higher ( $58 \%$ vs. $21 \%, P=0.001), O_{2}$ saturation $(88.6 \pm 4.7 \%$ vs. $91.3 \pm 2.6 \%, P=0.012)$ was significantly lower and WBC means $\left(11.9 \pm 2 .{ }^{*} 10^{6} / \mathrm{I}\right.$ vs. $\left.9.3 \pm 1.8{ }^{*} 10^{6} / \mathrm{I}, \mathrm{P}<0.001\right)$ were remarkably higher in positive group cardiac biomarker compared to the other group. Other laboratory data including $\mathrm{Hb}$, BUN and Cr did not show any significant difference between two groups (Table2).

The ECG findings are summarized in Table 3. The mean QT interval was $482.25 \pm 19.57 \mathrm{msec}$ in male and $490.05 \pm 20.86 \mathrm{msec}$ in female. Abnormal ECG findings including inverted T in V1-V3 leads and long QT interval were more prevalent in positive group ( $83 \%$ vs. $16 \%, \mathrm{P}<0.001$ and $75 \%$ vs. $35 \%, \mathrm{P}=0.013$, respectively). In contrast, normal sinus rhythm was mostly observed in those with negative hs-Tnl.

Thirty patients $(50 \%)$ used methadone for the first time in a suicide attempt. There was no statistically significant correlation between increased hs-Tnl level with consumption of methadone for the first time or chronically use for Methadone Maintenance Treatment (MMT; data are not shown). 
Table 4 figured various cardiac parameters in echocardiography based on hs-Tnl results (positive - negative) on admission and $30^{\text {th }}$ day. Diastolic dysfunction was not significantly different between positive and negative hs-Tnl case groups. Patients with positive hs-Tnl level on admission significantly had lower LVEF

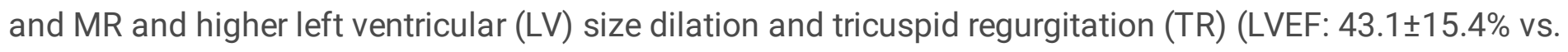
$55 \%, \mathrm{P}<0.001$, MR: $50 \%$ vs. $63 \%, \mathrm{P}=0.041$, LV size dilation: $42 \%$ vs. $0 \%, \mathrm{P}<0.001, \mathrm{TR}: 50 \%$ vs. $15 \%, \mathrm{P}=0.008)$ in comparison with negative group. Alternatively, RWMA and PAP were surprisingly higher in positive group (42\% vs. $0, P<0.001$ and $33.3 \pm 9.3 \mathrm{mmHg}$ vs. $26.9 \pm 5.02 \mathrm{mmHg}, \mathrm{P}=0.002)$. The RWMA was non-territory and mostly observed in anterior wall.

After 30 days, LVEF and RWMA were lower and higher in individuals with positive hs-Tnl compared to negative ones $(43.7 \pm 21.6 \%$ vs. $55.3 \pm 1.2 \%, P<0.001$ and $25 \%$ vs. $4 \%, P=0.020)$ respectively. Although LVEF in patients with positive hs-Tnl raised to approximately normal means from baseline but this correlation was not significant.

\section{Discussion:}

The aim of this study was to evaluate hs-Tnl as a biomarker for cardiac injury in methadone toxicity .

In this study by electrocardiography and echocardiography it was shown that prevalence of long QT interval and inverted T waves in precordial leads in patients with positive hs-Tnl was higher than negative group.

Echocardiographic findings showed that heart function was worse in the positive group than in the negative group.

Due to widespread usage of methadone in MMT programs and consequent raised prevalence of methadone toxicity, precautions should be made in terms of cardiovascular events. We did not found any positive findings in terms of other hemodynamic parameters including SBP, DBP or respiratory rates between groups this may be due to receiving treatment by EMS before being admitted to the hospital.

Endogenous ligands for opiate receptors were recognized in 1970s and these peptides were reported to affect cardiac tissue resulting in bradycardia, hypotension and peripheral vasodilation or even hypertension and tachycardia. Some records suggest that enkephalins play a primary role in some cardiac pathological circumstances including ischemic pre-conditioning with potassium-adenosine triphosphate channels located in myocardial cells mitochondria $[20,21]$. The presence of sinus tachycardia in our study might be due to stimulation of these endogenous ligands.

Despite methadone is effective on all opioid receptors $(\kappa, \delta$ and $\mu)$, it basically act on $\mu$ receptor resulting in probable mimicking of endogenous opioids and block reuptake of substances including norepinephrine and serotonin in central nervous system [22-23].

Methadone cardiotoxicity is reported in the literature. Ehret et al. found methadone prolonged QT interval among consumers rather than non-consumers (16.2\% vs. $0, \mathrm{P}<0.001)$ and had correlation with daily methadone dosage (r: 0.20, P<0.01) [24]. Methadone blocks human ether-a-go-go-related gene (hERG1) leading to prolongation of phase 3 of ventricular action potential resulting in long QT interval and possible 
occurrence of torsade de pointes [25]. Bradycardia induced by anticholinesterase characteristics of methadone or early after depolarization occurrence because of calcium and sodium-calcium exchange channels could be categorized as other possible mechanism for incidence of torsade de pointes [26, 27]. In our study prolonged QT interval was observed in $43 \%$ of cases and patients with positive biomarker had higher prevalence of this finding. It seems that myocardial injury induced by methadone might be responsible for higher frequency of long QT interval. Sheibani et al., found ECG abnormalities in all of dead cases with no correlation between ST-T abnormalities and coronary disease in autopsy [11]. In addition to rhythm disorders, methadone has been reported to be associated with other cardiovascular events. For instance, Najafi followed 566 patients with prior coronary artery bypass graft for 6.5 years and figured out patients with positive pre-operation opium usage had lower LVEF. [28]

Although in our study LVEF of most of the patients became normal in 30th days of follow up but in some patients it remained lower, this finding might be due to close follow-up duration (thirty days). Additionally, the insignificancy of differences in LVEF between baseline and at the end of follow up among patients with positive high sensitive troponin might be due to small sample size. Considering that all patients with reduced LVEF had mild methadone toxicity, moderate and severe toxicity might be related with higher reduction in LVEF, so in severe cases of methadone toxicity this effect should be remember in mind in clinical settings.

Potential mechanisms of opium usage with occurrence of coronary artery diseases are reported in literature. Masoudkabir et al. reported that opium decreases plasma estrogen, testosterone, apolipoprotein A and increases insulin resistance, oxidative stress and inflammation, fibrinogen, factor VII as well as apolipoprotein B consequently leads to hypercoagulability status and increased likelihood of cardiovascular events [29]. However, we found no coronary lesions in patients underwent angiography. Gorgaslidze et al. enrolled 65 patients free of cardiovascular diseases who consumed opium and ephedrine. All participants underwent 24-hours Holter monitor and ECG as well as echocardiography. They suggested that these individuals had reduced LVEF, ventricular dilation and systolic shortening of cardiac fibers revealed in echocardiographic findings and proposed the potential relation between opium and declined myocardial function [30].

In our study, $42 \%(n=5)$ of patients with positive troponin had LV size dilation, this transient cardiomyopathy improved in most of the patients after 30 days. This phenomenon might be due to transient catecholamine surges induced by methadone usage ultimately caused takotsubo syndrome [30]. This stress cardiomyopathy mostly occurred due to emotional stress in presence of no obvious coronary artery lesions. A pediatric and adolescent cases have been reported to suffer from this type of cardiomyopathy [30, 31].

In our study, patients with positive hs-Tnl had higher means of PAPs. The relation of methadone with raised pressure in pulmonary arteries has been suggested in experimental studies. Maiante et al. selected six dogs to evaluate the cardio-pulmonary effects of morphine and two different dosages of methadone. They found that PAPs were significantly higher in dogs received any dosages of methadone compared to morphine takers after 30 minutes of injection. This phenomenon might be related to decreased heart rate or vasoconstriction induced by methadone injection. Moreover, higher prevalence of smoking and possible occurrence of bronchiectasis might be other explanations of higher PAP means [32]. 
Till now there are few studies assessing the probable association of hs-Tnl with methadone toxicity. Mostafavi et al. performed a cross-sectional study on 100 patients with simultaneous positive troponin and methadone toxicity to define the possible relation of this biomarker with probable coronary artery diseases.. Their final findings suggested that raised hs-Tnl levels in patients with methadone toxicity should not be defined as a manifestation of coronary artery syndromes [18]. Therefore, implementation of angiography must be performed based on patients' clinical status as well as ECG alterations. We performed angiography on two patients in this study because of suspicious ECG changes indicating ischemia as well as their clinical status. Sheibani et al., studied on 245 pure methadone toxicity cases and found that hs-Tnl had an independent significant association with mortality, with a cutoff value of $0.0365 \mathrm{ng} / \mathrm{mL}$ (odds ratio, 38.1; $95 \% \mathrm{Cl}, 2.3-641.9 ; \mathrm{P}<0.001)$ [33].

In current study, participants with positive troponin had higher WBC counts and lower LVEF compared to normal patients. This phenomenon might be partly explained by inflammatory cytokines and consequent effect on myocardial cells. Several complementary studies are required in this regard.

To best of our knowledge, current study is one of the the first in literature evaluating the relation of high sensitive troponin with ECG and echocardiographic findings in patients suffering from methadone toxicity.

It seems that methadone toxicity can lead to acute myocardial injury and should be investigated more in those with positive high sensitive troponin. However, by usage of other instruments including ECG, echocardiography and computed tomography (CT) coronary angiography as well as patient's clinical status, implementation of invasive procedures could be prevented, especially during coronavirus pandemic.

In conclusion, this study indicates that ECG and cardiac function were worse among patients with concurrent methadone toxicity and positive high sensitive troponin.

Therefore measurement of this biomarker could be effective for implementation of appropriate therapeutic interventions. Further studies are necessary confirming our findings.

\section{Limitations:}

Small sample size plus short follow-up duration might affect the generalization of our findings.

\section{Abbreviations}

BUN: blood urea nitrogen; Cl: Confidence Interval; Cr: creatinine; DBP: diastolic blood pressure; DPIC: drug and poison information center; ECG: electrocardiogram; $\mathrm{Hb}$ : hemoglobin; hs-Tnl: high-sensitivity troponin I; MI: myocardial infarction; MMT: methadone maintenance therapy; MR: mitral regurgitation; LV: left ventricular; LVEF: left ventricular ejection fraction; PAP: pulmonary arterial pressure; QT: Q-T interval in electrocardiogram; RWMA: regional wall motion abnormality; SBP: systolic blood pressure; SPSS: Statistical Package for Social Software; TDP: torsade de pointes; TR: tricuspid regurgitation; WBC: white blood cell

\section{Declarations}




\section{Ethical approval and consent to participate:}

All procedures performed in studies involving human participants were under the ethical standards of the institutional and/or national research committee, and with the 1964 Helsinki declaration and its later amendments or comparable ethical standards. Ethical committee of Isfahan University of Medical Sciences approved this study (IR.MUI.MED.REC.1398.342). Written informed consent was obtained from the patients. A copy of the written consent is available for review by the Editor-in-Chief of this journal

\section{Consent for publication:}

Written informed consent was obtained from the patients for their information to be published in this article.

\section{Availability of data and materials:}

The datasets generated during and/or analyzed during the current study are not publicly available due to confidential issues but are available from the corresponding author on reasonable request.

\section{Competing interests:}

The authors declare that they have no competing interests.

Funding: Isfahan University of Medical Sciences.

\section{Authors' contributions:}

FG is the guarantor of integrity of the entire study. HS and MS gave the study concepts and designed the study. ADD and FG did the literature research. MS and HS performed the data analysis. FG performed the statistical analysis. ADD prepared the manuscript draft and HS, MS and FG did edit the final manuscript. All authors have read and approved the manuscript.

\section{Acknowledgements}

The authors would like to thank all nurses of Clinical Toxicology and Cardiology Department of Khoorshid University Hospital for their valuable collaboration in the patient's management. This study is written based on thesis of Azadeh Davoudian Dehkordi

\section{Authors' information}

Hasan Shemirani: Professor of Cardiology, Department of Cardiology, School of Medicine, Isfahan University of Medical Sciences, Isfahan, Iran, Email address: shemirani@med.mui.ac.ir; https://orcid.org/0000-00028977-6360

Masoumeh Sadeghi: Professor of cardiology, Isfahan Cardiovascular Research Center, Isfahan University of Medical Sciences, Isfahan, Iran, Email address:sadeghimasoumeh@gmail.com; https://orcid.org/0000-00017179-5558 
Azadeh Davoudian Dehkordi: Resident of Cardiology, Department of Cardiology, School of Medicine, Isfahan University of Medical Sciences, Isfahan, Iran, Email address: dr.a.davoudiand@gmail.com;

https://orcid.org/0000-0002-6822-3863

Farzad Gheshlaghi: Professor of Clinical Toxicology, Department of Clinical Toxicology, School of Medicine, Isfahan University of Medical Sciences, Isfahan, Iran, Email address: gheshlaghi@med.mui.ac.ir

\section{References}

1. Alinejad S, Kazemi T, Zamani N, Hoffman RS, Mehrpour O. A systematic review of the cardiotoxicity of methadone. EXCLI Journal. 2015;14:577-600.

2. Ehret GB, Desmeules JA, Broers B. Methadone-associated long QT syndrome: improving pharmacotherapy for dependence on illegal opioids and lessons learned for pharmacology. Expert opinion on drug safety. 2007;6:289-03.

3. Vida Ayatollahi, Shokoufeh Behdad, Hamid Oliwiaie, Mohammad Reza Hajiesmaili, Maryam Dehghan, et al. Characteristic features of patients hospitalized with Narcotic poisoning in Yazd, Iran. Iranian journal of toxicology. 2011;4:362-66.

4. Hadeiy SK, Parhizgar P, Hassanian-Moghaddam H, Zamani N, Khoshkar A, Kolahi AA, Amirabadizadeh A, Rezaei 0 . Trends of acute drug and chemical toxicities in adults and adolescents in Tehran, Iran between 2012 and 2018: a retrospective chart review. Drug Chem Toxicol. 2021;16:1-10.

5. Soltaninejad K, Hassanian-Moghaddam H, Shadnia S. Methadone related poisoning on the rise in Tehran, Iran. Asia Pacific Journal of Medical Toxicology. 2014;3:104-109.

6. Shadnia S, Rahimi M, Hassanian-Moghaddam M, Soltaninejad K, Noroozi A. Methadone toxicity: comparing tablet and syrup formulations during a decade in an academic poison center of Iran. Clinical Toxicology. 2013; 51:777-782.

7. Hassanian-Moghaddam H, Hakiminejhad M, Farnaghi F, Mirafzal A, Zamani N, Kabir A. Eleven years of children methadone poisoning in a referral center: A review of 453 cases. Journal of opioid management. 2017;13:27-36.

8. Jafari S, Rahimi-Movaghar A, Craib KJ, Baharlou S, Mathias R. A follow-up study of drug users in Southern Iran. Addiction Research \& Theory 2010;18(1):59-70.

9. Eap CB, Buclin T, Baumann P. Interindividual variability of the clinical pharmacokinetics of methadone. Clinical pharmacokinetics 2002;41(14):1153-93.

10. Corkery JM, Schifano F, Ghodse AH, Oyefeso A. The effects of methadone and its role in fatalities. Human Psychopharmacology: Clinical and Experimental 2004;19(8):565-76.

11. Sheibani M, Zamani N, Hassanian- Moghaddam H. Electrocardiographic findings in mortalities due to pure methadone toxicity. Cardiovasc Toxicol. 2019;19:62-71.

12. Farsi D, Mirafzal A, Hassanian-Moghaddam H, Azizi Z, Jamshidnejad N, Zehtabchi S. The correlation between prolonged corrected QT in-terval with the frequency of respiratory arrest, endotracheal intuba-tion, and mortality in acute methadone overdose. Cardiovasc Toxicol. 2014;14:358-367. 
13. Hamilton TT, Huber LM, Jessen ME. PulseCO: a less-invasive method to monitor cardiac output from arterial pressure after cardiac surgery. Ann Thorac Surg. 2002;74:S1408-12.

14. Gorgaslidze A, Saĭfullaeva M, Kuz'mina M, Golitsina L, Smetnev A. Cardiac arrhythmia and myocardial contraction in opium and ephedrone addiction. Kardiologiia. 1993;33:14-16.

15. Darabad BR, Vatandust J, Khoshknab MP, Poorrafsanjani MH. Survey of the effect of opioid abuse on the extent of coronary artery diseases. Global journal of health science. 2014;6:83-91.

16. Masoomi M, Ramezani MA, Karimzadeh $\mathrm{H}$. The relationship of opium addiction with coronary artery disease. International Journal of Preventive Medicine. 2010;1:182-86.

17. Dehghani F, Masoomi M, Haghdoost AA. Relation of opium addiction with the severity and extension of myocardial infarction and its related mortality. Addiction \& health. 2013;5:35-42.

18. Mostafavi A, Mottaghi MH, Tabatabaei SAH. Evaluation of the Significance of Positive Troponin I in Patients With Methadone Toxicity. Iranian Heart Journal. 2020;21:119-27.

19. Lewis S. Nelson and Dean Olsen ,OPIOIDS.In:, Lewis S. Nelson, Mary Ann Howland, Neal A. Lewin, Silas W. Smith, Lewis R. Goldfrank, and Robert S. Hoffman. Goldfrank's Toxicologic Emergencies.11th ed. New York: McGraw-Hill Education ;2019. P 1793-62.

20. Van Den Brink OW, Delbridge LM, Rosenfeldt FL, Penny D, Esmore DS, Quick D, et al. Endogenous cardiac opioids: enkephalins in adaptation and protection of the heart. Heart, Lung and Circulation 2003;12(3):178-87.

21. Gross ER, Hsu AK, Gross GJ. Opioid-induced cardioprotection occurs via glycogen synthase kinase $\beta$ inhibition during reperfusion in intact rat hearts. Circulation research 2004;94(7):960-66.

22. Ratcliffe SG. Methadone poisoning in a child. British medical journal 1963;1(5337):1069-70.

23. Albion C, Shkrum M, Cairns J. Contributing factors to methadone-related deaths in Ontario. The American journal of forensic medicine and pathology 2010;31(4):313-19.

24. Ehret GB, Voide C, Gex-Fabry M, Chabert J, Shah D, Broers B, et al. Drug-induced long QT syndrome in injection drug users receiving methadone: high frequency in hospitalized patients and risk factors. Archives of internal medicine 2006;166(12):1280-87.

25. Izadi-Mood N, Gheshlaghi F, Salehi Mehrdad AH.Comparative evaluation of different methadone dosage on QT interval. J Iran Soc Anaesth Intens Care 2008;62:7-13.

26. Kannankeril PJ, Roden DM. Drug-induced long QT and torsade de pointes: recent advances. Current opinion in cardiology 2007;22(1):39-43.

27. Mujtaba S, Romero J, Taub CC. Methadone, QTc prolongation and torsades de pointes: current concepts, management and a hidden twist in the tale? Journal of Cardiovascular Disease Research 2013;4(4):22935.

28. Najafi M, Jahangiry L, Mortazavi SH, Jalali A, Karimi A, Bozorgi A. Outcomes and long-term survival of coronary artery surgery: The controversial role of opium as risk marker. World journal of cardiology 2016;8(11):676-83.

29. Masoudkabir F, Sarrafzadegan N, Eisenberg MJ. Effects of opium consumption on cardiometabolic diseases. Nature reviews Cardiology 2013;10(12):733-40. 
30. Zavar R, Vakhshoori M, Mirmohammadsadeghi M, Hashemi-Jazi M. A rare case of takotsubo syndrome led to intra-myocardial dissection and left ventricular apical aneurysm. ARYA atherosclerosis 2019;15(1):33-37.

31. Dehghani K, Shojaie M, Pourdavood AH, Khajouei M. Stress Cardiomyopathy (Takotsubo syndrome) Following Accidental Methadone Poisoning; Report of Two Pediatric Cases. Archives of Academic Emergency Medicine 2019;7(1):e22.

32. Maiante A, Teixeira Neto FJ, Beier S, Corrente J, Pedroso C. Comparison of the cardio-respiratory effects of methadone and morphine in conscious dogs. Journal of veterinary pharmacology and therapeutics 2009;32(4):317-

33. Sheibani M, Mirfallah Nassiri AA, Abedtash A, McDonald R, Zamani N, Hassanian-Moghaddam H. Troponin, A Predictor of Mortality in Methadone Exposure: An Observational Prospective Study. J Am Heart Assoc. 2021;10:e018899.

\section{Tables}

Table 1. General characteristics of cases according to hs-troponin groups.

\begin{tabular}{|lllll|}
\hline Variables & $\begin{array}{l}\text { Total } \\
(\mathrm{n}=60)\end{array}$ & $\begin{array}{l}\text { Hs-troponin } \\
\text { positive } \\
(\mathrm{n}=12)\end{array}$ & $\begin{array}{l}\text { Hs-troponin } \\
\text { negative } \\
(\mathrm{n}=48)\end{array}$ & \begin{tabular}{l} 
Value \\
\hline Age (years)
\end{tabular} \\
\hline Males N(\%) & $34.5 \pm 11.1$ & $37.1 \pm 14.6$ & $33.9 \pm 10.2$ & 0.369 \\
\hline Unemployed N(\%) & $40(66)$ & $8(66)$ & $32(66)$ & 0.641 \\
\hline Cigarette smoking N(\%) & $26(43)$ & $7(58)$ & $19(39)$ & 0.436 \\
\hline $\begin{array}{l}\text { Cigarette smoking duration } \\
\text { (pack/year) }\end{array}$ & $38(63)$ & $8(66)$ & $30(62)$ & 0.789 \\
\hline Hubble-bubble usage N(\%) & $10.2 \pm 15.9$ & $15.6 \pm 23.1$ & $8.8 \pm 13.5$ & 0.186 \\
\hline Alcohol consumption N(\%) & $31(51)$ & $7(58)$ & $24(50)$ & 0.605 \\
\hline Methadone usage N(\%) & $13(21)$ & $7(58)$ & $6(12)$ & 0.001 \\
\hline $\begin{array}{l}\text { Methadone usage duration } \\
\text { (months) }\end{array}$ & $30(50)$ & $8(66)$ & $22(45)$ & 0.197 \\
\hline Methadone consumption $(\mathrm{mg})$ & $17.6 \pm 22.8$ & $25.5 \pm 29.1$ & $15.6 \pm 21.0$ & 0.185 \\
\hline
\end{tabular}

Hs-Troponin: high sensitive troponin, ECG: electrocardiogram

Table2. Vital signs and laboratory findings of cases according to hs-troponin groups on admission 


\begin{tabular}{|c|c|c|c|c|}
\hline Variables & $\begin{array}{l}\text { Total } \\
(n=60)\end{array}$ & $\begin{array}{l}\text { Hs-troponin } \\
\text { positive } \\
(n=12)\end{array}$ & $\begin{array}{l}\text { Hs-troponin } \\
\text { negative } \\
(n=48)\end{array}$ & $\begin{array}{l}\mathrm{P} \\
\text { Value }\end{array}$ \\
\hline Heart rates (beats/minute) & $100.0 \pm 15.0$ & $107.6 \pm 15.7$ & $98.1 \pm 14.5$ & 0.050 \\
\hline Systolic blood pressure $(\mathrm{mmHg})$ & $112.9 \pm 10.5$ & $110.9 \pm 15.6$ & $113.4 \pm 9.0$ & 0.472 \\
\hline $\begin{array}{l}\text { Diastolic blood pressure } \\
(\mathrm{mmHg})\end{array}$ & $70.6 \pm 8.2$ & $70.2 \pm 11.0$ & $70.7 \pm 7.5$ & 0.846 \\
\hline Respiratory rate (rates/minute) & $11.6 \pm 1.4$ & $11.0 \pm 1.4$ & $11.7 \pm 1.3$ & 0.123 \\
\hline $\mathrm{O}_{2}$ saturation $(\%)$ & $90.8 \pm 3.3$ & $88.6 \pm 4.7$ & $91.3 \pm 2.6$ & 0.012 \\
\hline Hemoglobin $(\mathrm{g} / \mathrm{dl})$ & $14.3 \pm 1.4$ & $14.7 \pm 1.8$ & $14.2 \pm 1.2$ & 0.255 \\
\hline White blood cells $\left(10^{6} / \mathrm{I}\right)$ & $9.8 \pm 2.1$ & $11.9 \pm 2.2$ & $9.3 \pm 1.8$ & $<0.001$ \\
\hline Blood urea nitrogen $(\mathrm{mg} / \mathrm{dl})$ & $26.7 \pm 8.8$ & $25.9 \pm 9.2$ & $26.8 \pm 8.8$ & 0.746 \\
\hline Creatinine $(\mathrm{mg} / \mathrm{dl})$ & $0.84 \pm 0.14$ & $0.87 \pm 0.17$ & $0.83 \pm 0.14$ & 0.386 \\
\hline
\end{tabular}

Hs-Troponin: high sensitive troponin, ECG: electrocardiogram

Table 3. Electrocardiography Findings according to hs-troponin groups.

\begin{tabular}{|c|c|c|c|c|c|}
\hline \multicolumn{2}{|l|}{ Variables } & \multirow{2}{*}{$\begin{array}{l}\text { Total } \\
(n=60)\end{array}$} & \multirow{2}{*}{$\begin{array}{l}\text { Hs-troponin } \\
\text { positive } \\
(\mathrm{n}=12)\end{array}$} & \multirow{2}{*}{$\begin{array}{l}\text { Hs-troponin } \\
\text { negative } \\
(n=48)\end{array}$} & \multirow{2}{*}{$\begin{array}{l}\mathrm{P} \\
\text { Value }\end{array}$} \\
\hline & & & & & \\
\hline \multirow{6}{*}{$\begin{array}{l}\text { Electrocardiography } \\
\text { Findings }(\%)\end{array}$} & Normal & $20(33)$ & $1(8)$ & 19(39) & 0.040 \\
\hline & $\begin{array}{l}\text { Sinus } \\
\text { tachycardia }\end{array}$ & $31(52)$ & $9(75)$ & $22(46)$ & 0.071 \\
\hline & $\begin{array}{l}\text { Inverted T in V1- } \\
\text { V3 }\end{array}$ & $18(30)$ & 10(83) & $8(16)$ & $<0.001$ \\
\hline & Long QT interval & $26(43)$ & $9(75)$ & $17(35)$ & 0.013 \\
\hline & $\begin{array}{l}\text { Inverted T in II, } \\
\text { III, avF }\end{array}$ & $1(1)$ & $1(8)$ & 0 & 0.044 \\
\hline & QRS variations & $1(1)$ & $1(8)$ & 0 & 0.044 \\
\hline
\end{tabular}

Hs-Troponin: high sensitive troponin,

Table 4. Distribution of cardiac outcomes at baseline and $\mathbf{3 0}$ days after study initiation across different categories hs-troponin. 


\begin{tabular}{|c|c|c|c|c|c|c|c|c|}
\hline \multirow[t]{2}{*}{ Endpoint } & \multicolumn{2}{|c|}{$\begin{array}{l}\text { Hs-troponin positive } \\
(n=12)\end{array}$} & \multirow[t]{2}{*}{$P^{*}$} & \multicolumn{2}{|c|}{$\begin{array}{l}\text { Hs-troponin negative } \\
(\mathrm{n}=48)\end{array}$} & \multirow[t]{2}{*}{$P^{*}$} & \multirow[t]{2}{*}{$P^{9}$} & \multirow[t]{2}{*}{$P^{\mathbb{}}$} \\
\hline & Baseline & $\begin{array}{l}\text { After } 30 \\
\text { days }\end{array}$ & & Baseline & $\begin{array}{l}\text { After } 30 \\
\text { days }\end{array}$ & & & \\
\hline LVEF (\%) & $43.1 \pm 15.4$ & $43.7 \pm 21.6$ & 0.878 & 55 & $55.3 \pm 1.2$ & 0.083 & $<0.001$ & $<0.001$ \\
\hline $\begin{array}{l}\text { Diastolic } \\
\text { dysfunction } \\
(\%)\end{array}$ & $3(25)$ & $2(17)$ & 0.317 & $4(8)$ & $4(8)$ & 0.346 & 0.108 & 0.389 \\
\hline $\begin{array}{l}\text { Regional wall } \\
\text { motion } \\
\text { abnormalities } \\
(\%)\end{array}$ & $5(42)$ & $3(25)$ & 0.483 & $0(0)$ & 2(4) & 0.511 & $<0.001$ & 0.020 \\
\hline $\begin{array}{l}\text { LV size } \\
\text { dilation (\%) }\end{array}$ & $5(42)$ & $2(17)$ & 0.375 & 0 & 0 & 1.00 & $<0.001$ & 0.004 \\
\hline $\begin{array}{l}\text { Mitral } \\
\text { regurgitation } \\
\text { (\%) }\end{array}$ & $6(50)$ & $5(42)$ & 0.157 & $10(63)$ & $10(21)$ & 0.125 & 0.041 & 0.136 \\
\hline $\begin{array}{l}\text { Tricuspid } \\
\text { regurgitation } \\
\text { (\%) }\end{array}$ & $6(50)$ & $4(33)$ & 0.572 & $7(15)$ & $7(15)$ & 0.553 & 0.008 & 0.133 \\
\hline $\begin{array}{l}\text { Pulmonary } \\
\text { arterial } \\
\text { pressure } \\
(\mathrm{mmHg})\end{array}$ & $33.3 \pm 9.3$ & $32.9 \pm 8.9$ & 0.586 & $26.9 \pm 5.02$ & $28.9 \pm 5.9$ & 0.014 & 0.002 & 0.051 \\
\hline
\end{tabular}

Hs-Troponin: high sensitive troponin, LVEF: left ventricular ejection fraction, LV: left ventricle

* $P$ value between baseline and after 30 days

q $\mathrm{P}$ value between hs-troponin positive and negative group at baseline

$\triangle \mathrm{P}$ value between hs-troponin positive and negative group after 30 days 